\title{
Perspectives of Teachers on Autism Spectrum Disorders (ASD) in Nepal
}

\author{
Sharan Hari Shrestha \\ Central Department of Education, TU
}

\begin{abstract}
This study aimed to explore the knowledge, awareness, and attitude of teachers regarding ASD and educating children with ASD. The research was conducted through quantitative method utilizing a survey design in this study. Seventy six teachers from seven special and twelve integrated schools from Kathmandu valley were selected through purposive sampling method. A Likert Scale with a 5-point survey instrument (questionnaire) was created and implemented. The data from the questionnaire were analyzed with descriptive statistics. Result of this study demonstrated that teachers of Nepal have the general idea of ASD but they don't possess in-depth knowledge regarding ASD. In this study, most of the teachers thought that students with ASD should be placed in special education classroom rather than general and inclusive classroom. Moreover, Nepalese teachers don't think they are prepared to educate students with ASD in their classes and also claimed teachers need additional training, seminar and workshop concerning ASD. Furthermore, the teachers of Nepal have limited knowledge, awareness, understanding, attitudes, placement services, and teaching readiness towards ASD. However, they have the basic knowledge and understanding of ASD.
\end{abstract}

Key Words: Autism Spectrum Disorder, Perspective, Knowledge, Awareness, Attitude.

\section{Introduction}

The word "autism" comes from the Greek word 'autos', meaning "self". "Children with Autism Spectrum Disorder (ASD) habitually are self-absorbed and appear to live in a personal world in which they are incapable of successfully communicating and interacting with others" (National Institute of Health, 2012). Persons with ASD might have complexity developing significant language skills and considering what other people say to them (receptive language). They might also have complexity conversing nonverbally, e.g. through expressions, eye contact, and hand signals. Complexity in communicating is a central symptom of ASD (Labarbera, 2019). 'Autos' is also the basis for the word 'automatic' which is associated with autonomous functioning with no need for external effort (like an automatic transmission or an automatic dishwasher). Kanner perceived the children as indicating only a small need for interaction with other people and perceived them as being self-absorbed and self-satisfied. Therefore, he utilized the term autism to distinguish the children's behaviors (Volkmar, Carter, Grossman, \& Klin, 1997 as cited in Helfin \& Alaimo, 2014). 
Autism isn't a novel disability. Individuals have displayed the symptoms linked with ASD for many years. In olden days, kids born with ASD possibly experienced a similar outcome faced by children born with whichever disability. Newborns and children seen as imperfect were deserted in isolated area and left to perish (Kirk, Gallagher, \& Anastasiow, 1993 as cited in Jung \& Shrestha, 2018). ASD initially gained interest by Leo Kanner in 1943, and he was a psychiatrist at John Hopkins University. He illustrated a set of children who did not connect to others, had setbacks in speech advancement, displayed recurring behavior, and were distressed by changes in routines (Kirk, Gallagher \& Coleman, 2015).

Autism Spectrum Disorder (ASD) is distinguished by a 'spectrum' character which incorporated complexity in social communication and relations, and oddly constricted, recurring behaviors (Meng-Chuan, Lombardo, Chakrabarti \& Baron-Cohen, 2013 as cited in Jung \& Shrestha, 2018). This set of people demonstrates impairment in communication and social behavior even with a typical IQ level or above. They also have a possibility for developing troublesome and other difficult behaviors that restrict classroom adaptation and social interaction with other individuals. It was established that coaching students with ASD in standard classroom settings is most demanding for teachers in regular schools (Frederickson \& Cline, 2009; Jung \& Shrestha, 2018).

ASD is a developmental disorder distinguished by a myriad of impairments in communication, socialization, and behavior. ASD, which the term "spectrum" means broad range of impairment, symptoms or disability that persons with ASD may have, are linked with quite a few impairments in explicit developmental areas such as social interaction ability, verbal and non-verbal communication ability and distinguished by stereotyped or monotonous behaviors, activities and interests, beginning earlier than 36 months (Levy, Mandell \& Schultz, 2009; Baglama \& Demirok, 2014; as cited in Jung \& Shrestha, 2018). Lately, there are a few changes in the definition and substance of ASDs. In the newest edition of the Diagnostic and Statistical Manual of Mental Disorders (DSM-5), the symptoms linked with autism spectrum disorders emerge in a continuum in which persons might feel the symptoms in diverse ways like mild or severe (American Psychiatric Association, 2013). In DSM- IV, ASD analysis was founded on a myriad of symptoms, like language impediment, social communication shortfall, and recurring or restraining behaviors. According to DSM- 5 criterion, ASD diagnosis guiding principles contain two (2) domains of criteria i.e. social interaction (such as language and social discrepancy) and recurrent or constrictive behavior.

Educators who work with students with autism must have the substance knowledge, common pedagogical knowledge, curriculum information, knowledge about students and their character, knowledge of educational circumstance, and knowledge of educational aims and principles (Yasar \& Cronin, 2014; Mehring \& Dow, 2001; Jung \& Shrestha, 2018). Siu and Ho (2010) said that some educators don't feel certain enough to educate children with ASD. Educators believe they need additional training, tools, knowledge, and skills to deal with such children.

Each nation has its own standards to classify particular types of disabilities. It implies that categorization of disability in one nation may not bear a resemblance to the other. In the 
Nepalese context, disability is grouped into seven types which are: physical disabilities, visual impairment, hearing impairment, deaf blind, speech disorder, mental disability and multiple disability (Central Bureau of Statistics, 2012), and ASD is included in mental disability in Nepal (Curriculum Development Center, 2016; National Center for Educational Development, 2016), which hinders steady development of children according to their age. In Nepal's case, the children who demonstrate strange reaction, repeat again and again identical behavior, don't demonstrate any concern in social interaction, and convey spontaneous reactions are deemed as children with ASD (NCED, 2016). These days, Nepalese Government has launched ASD as a distinct disability type with the passing of Inclusive Education Policy, 2017 (Jung \& Shrestha, 2018).

It is important for experts to be familiar with the signs and symptoms of autism and features of children with ASD to help and recognize children who may require additional evaluation to settle on whether they have ASD. Besides this, knowing significant features of children with autism has key repercussions for instructive and environmental planning (Koegel \& Koegel, 1995 as cited in Rakap, Balikci, Parlak-Rakap, 2016). Research has exposed that educators' expectations regarding students with disabilities, as well as those with autism, affect their teaching goals, techniques, and educational practices (Lane, Carter, Common, \& Jordan, 2012 ; Rakap et al., 2016).

Educators' attitudes and perceptions regarding Autism is a significant feature for the students' education. Attitude is described as conduct, temperament, emotion, positions etc. regarding an individual or thing; inclination or orientation, particularly of the mind (http://dictionary. reference. com). These are formed through learning by observation, parents and friends behaviors, and relations between past experience and the people's environment (Park, Chitiyi, \& Choi, 2012 as cited in Yasar \& Cronin, 2014). Teachers ' thinking, perception and attitudes regarding their students influences educational results of the students. As per Gargiulo (2003), he described attitudes as an inclination to treat in a constructive or adverse way towards a specified attitude object. Likewise, Rodriguez Saldana \& Moreno, 2011; Robertson, Chamberlain \& Kasari, 2003 mentioned that good teacher attitudes are taken as an important forecaster of fruitful education of students with disabilities, even those with autism. Moreover, communication method of the educator like firm and social styles is also a significant forecaster of the attitudes of children towards the lesson (Urea, 2013).

Since awareness and knowledge regarding Autism improved globally, education of students with Autism and more inclusive education for educators of ASD students becomes more essential (Yasar \& Cronin, 2014). Consequently, timely diagnosis and timely educational interventions for Autism must be more appropriate. It is also acknowledged that while students with Autism enter instructive programs at younger ages, they would have more benefits as compared to students who entered instructive programs at more senior ages (Harris \& Handleman, 2000).

In Nepal, there is no exact official data of ASD population till this date. Community people as well as intellectuals of Nepal have lack of awareness and knowledge about ASD because of deeply rooted social superstitions, social taboo and enormously new concept and subject (Jung $\&$ Shrestha, 2018). Furthermore, the nation does not have a nationwide system for referring, 
screening, identifying, and diagnosing children with ASD (Matson \& Kozlowski, 2011; Weintraub, 2011: Jung \& Shrestha, 2018). In Nepal also, ASD is rarely diagnose due to lack of skilled professionals in this field. Even government and intellectuals have been giving little attention in academia. Moreover, community people, parents of children with ASD also have not much knowledge and awareness about ASD. Many Nepalese parents of children with ASD have no choice as school did not accept children with ASD due to lacks of plans, policies, and programs of the nation (Jung \& Shrestha, 2018). Taking account of the situation, this study will find out the perspectives of teachers on ASD in Nepal.

\section{Problem Statement}

In Nepal, there is lack of knowledge and understanding among not just the individuals and society but also academic people like educators and government officials mainly due to the fact that Nepal is still deeply rooted in superstitions, social dogmas, and misconceptions. Thus, all of them have misconceptions and misunderstanding regarding ASD. Educators and academicians also believe that ASD is an illness as ASD is an exceptionally novel concept and has been categorized as a brand new disability. Yet, Nepalese government had also launched ASD as a distinct category of disability after the launch of the Special Education Policy, 2017. It was incorporated with mental disability. So, it can be said that there is lack of knowledge and awareness about ASD in Nepal (Jung \& Shrestha, 2018). In this scenario, this study will be successful and capable to investigate the teachers' awareness, knowledge and attitude towards ASD in Nepal. One of the most important but cosmopolitan problems in Nepalese education is associated with the way of delivery by teachers between students with ASD and without ASD. On spot observations and analyses show not much considerable difference prevails in regards educating by teachers to the children with ASD and children without ASD.

\section{Objectives and Research Questions}

The central objective of this study was to assess awareness, knowledge, and attitude of educators regarding ASD and educating children with ASD. This study is a survey which was implemented within Kathmandu valley, Nepal with teachers of special and integrated schools in the duration of the training period. Respondents (teachers) answers were observed or assessed to get answers to the following research questions:

I. What knowledge do teachers have about ASD?

ii. Are teachers aware of ASD and educational needs of children with ASD?

iii. Do the teachers identify the placement of child with ASD?

iv. Do the teachers believe they are prepared to educate students with ASD in their classes?

\section{Research Method}

This study was conducted through a quantitative research method (Cresswell, 2012) which was followed by survey research design (Kaul, 2009). The convenient sampling was used in this study. Seventy six (76) teachers belonging to seven (7) special and twelve (12) integrated schools within Kathmandu Valley were chosen through purposeful selection (Singh, 2006). The survey instrument (questionnaire) consisting of a 5-points Likert Scale was created and conducted through descriptive statistics. To make sure the reliability and validity of the instrument, first 
of all, it was created by means of equal parts of both positive and negative statements. Next, suggestions from colleagues and professor were considered and the instrument was redone according to the recommendations. Then, a pilot test was on small sample size of 10 teachers was conducted. After analyzing the outcome of the pilot test, the instrument was again thoroughly amended to reduce errors and the Cronbach's alpha obtained was 0.75. After completing these procedures, lastly questionnaire was given to the survey group. The survey was conducted on the teachers in the training time. The questionnaire consisted of a 5 points Likert scale answer format in which 1 = strongly disagree; 2 = disagree; 3 = neither agree nor disagree; $4=$ agree, and 5 strongly agree for positive statement. Contrarily, 1 implied strongly agree, 2 implied agree, 3 implied neither agree nor disagree, 4 implied disagree, and 5 implied strongly disagree for negative statements. English and Nepali, both types of the languages was utilized while carrying out the study since the first language of the respondents was Nepali and a few teachers were not able to comprehend English language. The questionnaire comprised of 20 statements which inquire about view, knowledge, awareness and associated issues with ASD. Participants took about 30 minutes to finish the questionnaires. For analysis of the data, descriptive statistics (Mean and S.D.) were used (Bodgan and Biklen, 2007) with the help of IBM SPSS version 25 Program and Microsoft Office Excel 2007.

Table 1: Participants of the Study

\begin{tabular}{|l|l|c|c|}
\hline \multicolumn{2}{|c|}{ Criteria } & Number & Percent \\
\hline \multirow{2}{*}{ Gender } & Male & 27 & 35.53 \\
\cline { 2 - 4 } & Female & 49 & 64.47 \\
\hline \multirow{2}{*}{ Age } & Below 25 yrs. & 11 & 14.47 \\
\cline { 2 - 4 } & Above 26 yrs. & 65 & 85.53 \\
\hline \multirow{3}{*}{ Tystrict } & Kathmandu & 30 & 39.47 \\
\cline { 2 - 4 } & Lalitpur & 26 & 34.21 \\
\cline { 2 - 4 } & Bhaktapur & 20 & 26.32 \\
\hline \multirow{2}{*}{ Categories of Teacher } & Special & 7 & 36.84 \\
\cline { 2 - 4 } & Integrated & 12 & 63.16 \\
\cline { 2 - 4 } & Disable & 8 & 10.53 \\
\cline { 2 - 4 } & Non-disable & 68 & 89.47 \\
\hline
\end{tabular}

As shown in Table 1, approximately $35.53 \%$ of the respondents were men and $64.47 \%$ of the teachers were women. Here, the numbers of women teachers are larger than the number of men teachers. Likewise, $14.47 \%$ teachers as respondents of this study were lesser than 25 years and $85.53 \%$ of respondents were more than the age of 26 years. Similarly, it is displayed that $39.47 \%$ of the respondents were from Kathmandu, 34.21\% were from Latitpur and 26.32\% were from Bhaktapur. As per the table, the largest numbers of respondents were from Kathmandu districts. Additionally, 36.84\% were from special needs schools and $63.16 \%$ were form integrated schools. Lastly, it can be concluded that integrated schools are greater than special schools. Likewise, $10.53 \%$ of disabled teachers were respondents in this study and $89.47 \%$ of them were nondisabled. Therefore, non-disabled teachers numbered more than disabled teachers.

The following table presents the score ranges used in the scale: 
Perspectives of Teachers on Autism Spectrum Disorders (ASD) in Nepal/ 195

Table 2: Load of the Scale

\begin{tabular}{|l|c|c|}
\hline \multicolumn{1}{|c|}{ Opinion } & Load for Positive Statement & Load for Negative Statement \\
\hline Strongly Disagree & 1 & 5 \\
\hline Disagree & 2 & 4 \\
\hline Neither Agree nor Disagree & 3 & 3 \\
\hline Agree & 4 & 2 \\
\hline Strongly Agree & 5 & 1 \\
\hline
\end{tabular}

\section{Results}

\section{Descriptive Statistics for Each Statement}

The data taken from the questionnaire instrument were scrutinized with descriptive statistics to find out the mean and standard deviation of the teachers of special and integrated schools' evaluating the Likert scale rated statements. A five points Likert scale indicated answers from 1 which implied Strongly disagree to 5 which implied strongly agree for positive statements and 1 implied Strongly agree to 5 which implied Strongly disagree for negative statements. The statements of the survey were created to give answers to the research questions and give substantial information on teachers' attitudes, knowledge, awareness, and placement skills to children with ASD. Descriptive statistics were calculated for each statement which is given in Table 3 .

Table 3: Rating Scale for Each Statement

\begin{tabular}{|c|c|c|c|c|}
\hline S.N. & Area & Statement & Mean & $S D$ \\
\hline 1 & \multirow{6}{*}{ Knowledge of ASD } & $\begin{array}{l}\text { Autism Spectrum Disorder (ASD) is considered } \\
\text { as a neuro developmental disorder that can be } \\
\text { improved through education. }\end{array}$ & 3.36 & 0.94 \\
\hline 2 & & $\begin{array}{l}\text { Children with ASD do not have feeling and } \\
\text { emotions. }\end{array}$ & 2.05 & 0.56 \\
\hline 3 & & $\begin{array}{l}\text { I am able to provide information about ASD when } \\
\text { the people ask. }\end{array}$ & 2.86 & 1.34 \\
\hline 4 & & There is no cure for ASD but ways to treat it. & 4.01 & 1.19 \\
\hline 5 & & \begin{tabular}{|l}
$\begin{array}{l}\text { All children with ASD do not show same } \\
\text { behaviors. }\end{array}$ \\
behow
\end{tabular} & 3.30 & 1.34 \\
\hline 6 & & $\begin{array}{l}\text { I am able to identify and understand the } \\
\text { characteristics of ASD. }\end{array}$ & 3.14 & 1.17 \\
\hline 7 & \multirow{6}{*}{$\begin{array}{l}\text { Awareness and } \\
\text { Educational Need } \\
\text { of Children with } \\
\text { ASD }\end{array}$} & $\begin{array}{l}\text { Students with ASD do not need communication } \\
\text { support. }\end{array}$ & 2.01 & 1.05 \\
\hline 8 & & $\begin{array}{l}\text { Visual supports do not help students who have } \\
\text { ASD. }\end{array}$ & 2.11 & 1.33 \\
\hline 9 & & $\begin{array}{l}\text { I know somebody (relatives, students, friends, and } \\
\text { others) who has ASD. }\end{array}$ & 3.77 & 1.27 \\
\hline 10 & & $\begin{array}{l}\text { I have not experience teaching a child with ASD } \\
\text { during my teaching period. }\end{array}$ & 1.75 & 1.22 \\
\hline 11 & & $\begin{array}{l}\text { Students with ASD do not need support to improve } \\
\text { their social skills. }\end{array}$ & 2.77 & 1.43 \\
\hline 12 & & Students with ASD need behavioral support. & 3.10 & 1.41 \\
\hline
\end{tabular}




\begin{tabular}{|c|c|c|c|c|}
\hline 13 & \multirow{3}{*}{$\begin{array}{l}\text { Placement of } \\
\text { Children with } \\
\text { ASD in Education } \\
\text { Settings }\end{array}$} & $\begin{array}{l}\text { Students with ASD should be placed in special } \\
\text { education classroom. }\end{array}$ & 4.50 & 0.88 \\
\hline 14 & & $\begin{array}{l}\text { Students with ASD should be placed in inclusive } \\
\text { classroom. }\end{array}$ & 2.78 & 1.25 \\
\hline 15 & & $\begin{array}{l}\text { Students with ASD should be placed in general } \\
\text { education classroom. }\end{array}$ & 2.39 & 1.42 \\
\hline 16 & \multirow{4}{*}{$\begin{array}{l}\text { Prepare to Teach } \\
\text { Children with ASD } \\
\text { in the Classroom }\end{array}$} & $\begin{array}{l}\text { I don't know how to deal with classroom } \\
\text { management issues in a class with student with } \\
\text { ASD }\end{array}$ & 3.09 & 1.49 \\
\hline 17 & & $\begin{array}{l}\text { I am able to plan a lesson which involves appropriate } \\
\text { learning activities for children with ASD. }\end{array}$ & 2.73 & 1.22 \\
\hline 18 & & $\begin{array}{l}\text { I am unable to integrate new teaching strategies in } \\
\text { classroom which contains a child with ASD. }\end{array}$ & 3.21 & 1.26 \\
\hline 19 & & $\begin{array}{l}\text { I have received enough knowledge, skills, and } \\
\text { education about ASD. So, I am ready to take class } \\
\text { children with ASD. }\end{array}$ & 2.43 & 1.39 \\
\hline 20 & $\begin{array}{l}\text { Need of Training, } \\
\text { Workshop and } \\
\text { Seminar }\end{array}$ & $\begin{array}{l}\text { Nepalese teachers should have more training, } \\
\text { seminar and workshop about ASD. }\end{array}$ & 4.26 & 0.98 \\
\hline
\end{tabular}

Table 4: Frequency and Percentage for Each Statement

\begin{tabular}{|c|c|c|c|c|c|c|c|c|c|c|}
\hline \multirow{2}{*}{ Statements } & \multicolumn{2}{|c|}{$\begin{array}{c}\text { Strongly } \\
\text { Agree }\end{array}$} & \multicolumn{2}{|c|}{ Agree } & \multicolumn{2}{|c|}{ Neutral } & \multicolumn{2}{|c|}{ Disagree } & \multicolumn{2}{|c|}{$\begin{array}{l}\text { Strongly } \\
\text { disagree }\end{array}$} \\
\hline & $\mathbf{N}$ & $\%$ & $\mathbf{N}$ & $\%$ & $\mathbf{N}$ & $\%$ & $\mathbf{N}$ & $\%$ & $\mathbf{N}$ & $\%$ \\
\hline Stmt 1 & 5 & 6.6 & 34 & 44.7 & 25 & 32.9 & 8 & 10.5 & 4 & 5.3 \\
\hline Stmt 2 & 8 & 10.5 & 32 & 42.1 & 14 & 18.4 & 20 & 26.3 & 2 & 2.6 \\
\hline Stmt 3 & 8 & 10.5 & 23 & 30.3 & 13 & 17.1 & 15 & 19.7 & 17 & 22.4 \\
\hline Stmt 4 & 38 & 50 & 14 & 18.4 & 14 & 18.4 & 7 & 9.2 & 3 & 3.9 \\
\hline Stmt 5 & 18 & 23.7 & 15 & 19.7 & 9 & 11.8 & 11 & 14.5 & 23 & 30.3 \\
\hline Stmt 6 & 5 & 6.6 & 31 & 40.8 & 22 & 28.9 & 6 & 7.9 & 12 & 15.8 \\
\hline Stmt 7 & 32 & 42.1 & 18 & 23.7 & 21 & 27.6 & 3 & 3.9 & 2 & 2.6 \\
\hline Stmt 8 & 38 & 50 & 12 & 15.8 & 9 & 11.8 & 13 & 17.1 & 4 & 5.3 \\
\hline Stmt 9 & 31 & 40.8 & 17 & 22.4 & 11 & 14.5 & 14 & 18.4 & 3 & 3.9 \\
\hline Stmt 10 & 49 & 64.5 & 11 & 14.5 & 7 & 9.2 & 4 & 5.3 & 5 & 6.6 \\
\hline Stmt 11 & 17 & 22.4 & 21 & 27.6 & 11 & 14.5 & 14 & 18.4 & 13 & 17.1 \\
\hline Stmt 12 & 14 & 18.4 & 24 & 31.6 & 7 & 9.2 & 18 & 23.7 & 13 & 17.1 \\
\hline Stmt 13 & 50 & 65.8 & 20 & 26.3 & 2 & 2.6 & 2 & 2.6 & 2 & 2.6 \\
\hline Stmt 14 & 7 & 9.2 & 16 & 21.1 & 23 & 30.3 & 14 & 18.4 & 16 & 21.1 \\
\hline
\end{tabular}


Perspectives of Teachers on Autism Spectrum Disorders (ASD) in Nepal/ 197

\begin{tabular}{|c|c|c|c|c|c|c|c|c|c|c|}
\hline Stmt 15 & 8 & 10.5 & 11 & 14.5 & 15 & 19.7 & 9 & 11.8 & 33 & 43.4 \\
\hline Stmt 16 & 13 & 17.1 & 21 & 27.6 & 9 & 11.8 & 12 & 15.8 & 21 & 27.6 \\
\hline Stmt 17 & 7 & 9.2 & 13 & 17.1 & 24 & 31.6 & 17 & 22.4 & 15 & 19.7 \\
\hline Stmt 18 & 8 & 10.5 & 11 & 14.5 & 27 & 35.5 & 13 & 17.1 & 17 & 22.4 \\
\hline Stmt 19 & 4 & 5.3 & 21 & 27.6 & 8 & 10.5 & 14 & 18.4 & 29 & 38.2 \\
\hline Stmt 20 & 38 & 50 & 29 & 38.2 & 2 & 2.6 & 5 & 6.6 & 2 & 2.6 \\
\hline
\end{tabular}

Table 3 and 4 provides in-depth information about descriptive statistics, frequency and percentage for each statement in the questionnaire. The first research question "What knowledge do teachers have about ASD?" was related to teachers' knowledge about ASD. Statements 1, 2, 3, 4, 5 \& 6 are mainly designed to find out the teachers' knowledge of ASD. According to the respondents for the first statement $(\mathrm{M}=3.36, \mathrm{SD}=0.94)$, thirty nine $(51.3 \%)$ participants reported that they agreed, twelve $(15.8 \%)$ participants disagreed and twenty five $(32.9 \%)$ participants reported that they neither agreed nor disagreed. So, most of the teachers have knowledge that ASD is regarded as as a neuro developmental disorder that can be improved through education.

For the second statement $(\mathrm{M}=2.05, \mathrm{SD}=0.56)$, forty $(52.6 \%)$ participants reported agree, twenty two $(28.9 \%)$ participants claimed disagree, and $14(18.4 \%)$ teachers claimed neither agree nor disagree. In other words, this result suggested that majority of the teachers' understanding were that children with ASD do not have feeling and emotions. Similarly, Statement 3 which was also related with knowledge of ASD $(\mathrm{M}=2.86, \mathrm{SD}=1.34)$, thirty one participants $(40.8 \%)$ teacher agreed, thirty two (42.1\%) participants disagreed, $13(17.1 \%)$ participants neither agreed nor disagreed. From these findings, it is claimed that only 40 percent teachers were able to provide information about ASD when people asked.

Likewise, statement 4 was also related with knowledge about ASD $(M=4.01, \mathrm{SD}=1.19)$. Fifty two $(68.4 \%)$ participants were reported that they agreed, only ten (13.1\%) participants answered disagree, 14 (18.4\%) participants reported neither agree nor disagree. Furthermore, statement $5(\mathrm{M}=3.30, \mathrm{SD}=1.34)$ also related with the first research question which was supported to knowledge of ASD. Thirty three (43.4\%) teachers reported that they agreed, thirty four $(44.8 \%)$ teachers disagreed, thirty four $(44.8 \%)$ teachers disagreed and nine $(11.8 \%)$ teachers reported that neither agreed nor disagreed. It means that, fifty percent teachers have the knowledge that all children with ASD do not show same behaviors.

Finally, statement 6 (where $\mathrm{M}=3.14, \mathrm{SD}=1.17$ ) is also related to the first research question. Thirty six (47.4\%) teachers claimed that they agreed, eighteen $(23.7 \%)$ teachers answered disagree and $22(28.9 \%)$ teachers stated neither agree nor disagree. Meaning, vast majority of teachers were capable to identify and understand the characteristics of ASD. Results of those six statements showed that teachers of Nepal have the general idea of ASD, but they do not have indepth knowledge of ASD. Therefore, it is generalized that participants were not confident about their understanding of ASD (See table 8 for whole statistics for each statement). 
Statements 7, 8, 9, 10, 11 and 12 were designed for second research question which was related to teachers' aware of ASD and educational needs of children with ASD. Among them statements 9 and 10 were designed to find out teachers' awareness of ASD and remaining statements 7, 8, 11 and 12 were intended to expose the awareness of educational needs of children with ASD. In statement $7(\mathrm{M}=2.01, \mathrm{SD}=1.05)$, fifty $(65.8 \%)$ teachers answered agree, only five $(6.5 \%)$ participants claimed disagree, and twenty one (27.6\%) participants reported neither agree nor disagree. So, a large portion of the participants reported that students with ASD do not need communication support. From this result it can be said that large numbers of Nepalese teachers have lack of awareness of educational needs of children with ASD.

Similarly, in statement $8(\mathrm{M}=2.11, \mathrm{SD}=1.33)$, thirty eight $(50 \%)$ teachers argued strongly agree, twelve $(15.8 \%)$ teachers stated agree, nine $(11.8 \%)$ teachers responded neither agree nor disagree, thirteen $(17.1 \%)$ teachers reported disagree and four $(5.3 \%)$ teachers claimed strongly disagree. Thus, most of the teachers understand that visual supports do not help students who have ASD. Only few (4 teachers) claimed that visual supports help students who have ASD. As a result, it is true that teachers of Nepal are not aware of ASD. Furthermore, in statement $9(\mathrm{M}=3.77,1.27)$, thirty one $(40.8 \%)$ teachers reported strongly agree, seventeen $(22.4 \%)$ teachers answered agree, eleven $(14.5 \%)$ teachers claimed neither agree nor disagree, fourteen (18.4\%) teachers argued disagree and $3(3.9 \%)$ teachers stated strongly disagree. Therefore, as per their answers, Nepalese teachers are able to identify the ASD children or people. Moreover, in statement $10(1.75, \mathrm{SD}=$ $1.22)$, forty nine $(64.5 \%)$ teachers reported strongly agree, $11(14.5 \%)$ teachers answered agree, seven (9.2) teachers claimed neither agree nor disagree, four (5.3\%) teachers argued disagree and five $(6.6 \%)$ teachers agreed strongly disagree. Consequently, it can be concluded that huge numbers of teachers had not experienced teaching to the children with ASD.

In the same way, in statement $11(\mathrm{M}=2.77, \mathrm{SD}=1.43)$, seventeen $(22.4 \%)$ teachers reported strongly agree, twenty one (27.6\%) teachers answered agree, eleven $(14.5 \%)$ teachers claimed neither agree nor disagree, fourteen (18.4\%) teachers answered disagree and thirteen $(17.1 \%)$ teachers responded strongly disagree. Thereby, most of the teachers claimed that students with ASD do not need support to improve their social skill. And then, in statement $12(\mathrm{M}=3.10, \mathrm{SD}=$ $1.41)$, fourteen $(18.4 \%)$ teachers respond strongly agree, twenty four $(31.6 \%)$ teachers answered agree, seven $(9.2 \%)$ teachers claimed neither agree nor disagree, eighteen $(23.7 \%)$ teachers reported disagree and thirteen $(17.1 \%)$ teachers argued strongly disagree. In other words, most of the teachers known that students with ASD need behavioral supports.

The third research question was "Do the teachers identify the placement of child with ASD in educational environment?" Statements 13, 14 and 15 were designed to get options about the placement of the children with ASD in educational settings. In statement $13(\mathrm{M}=4.50, \mathrm{SD}=$ $0.88)$, seventy $(92.1 \%)$ teachers reported agree, four $(5.2 \%)$ teachers answered disagree, and two $(2.6 \%)$ teachers claimed neither agree nor disagree. Undoubtedly, from the participant's responses, it can be said that most of the teachers had understood that students with ASD should be placed in special education classroom. Besides this, statement $14(\mathrm{M}=2.78, \mathrm{SD}=1.25)$ suggested students with ASD should be placed in inclusive classrooms. Twenty three $(30.3 \%)$ 
participants agreed, and $30(39.5 \%)$ participants' disagreed. Twenty three (30.3\%) participants' could not decide whether the students with ASD should be placed in inclusive classroom.

On the other hand, in statement 15, nineteen (25\%) participants agreed that students with ASD should be placed in general education classroom. Forty two (55.2\%) participants did not agree with these statement. $16(12.2 \%)$ participants reported neutral responses. However, the mean score for fifteen statement is 2.39 and $\mathrm{SD}=1.42$. Results of those three statements $(13,14$, and 15) showed that majority of the teachers who took part in this study believed that children with ASD should be placed in special education classroom rather than general and inclusive classroom or environment settings.

The fourth research question was "Do the teachers feel prepared to teach children with ASD in their classroom?" Statement 16, 17, 18 and 19 were designed for this research question. In statement 16 , Thirty four (44.7\%) participants agreed to the statement and thirty three $(43.4 \%)$ participants disagreed to the statement and nine (11.8\%) participants could not decide. So, they reported neither agree nor disagree. The mean scores and SD of this statement are 3.09 and 1.49 respectively.

In the same way, in statement 17 , twenty $(26.3 \%)$ participants reported agree, thirty two $(42.1 \%)$ participants answered disagreed and twenty four (31.6\%) reported neither agree nor disagree. Similarly, in statement 18 , nineteen (25\%) participants answered agree, thirty (39.5\%) participants reported disagree and twenty seven (35.5\%) participants claimed neither agree nor disagree. In the final stage, in statement 19 , twenty five $(32.9 \%)$ teachers reported agree, forty three $(56.6 \%)$ teachers answered disagree, and eight $(10.5 \%)$ teachers responded neither agree nor disagree.

From those four statements responses, it is clear that the Nepalese teachers are not ready to educate students with ASD in their classes. They are unable to manage the classroom for students with ASD, unable to plan lesson and lack of skill of appropriate learning activities, unable to integrate new teaching strategies in classroom, and lack appropriate knowledge, skills and education about ASD. So it can be seen that Nepalese teachers are not ready to teach children with ASD.

In addition to four research questions, the statement $20^{\text {th }}$ which advocated the necessities of training, seminar and workshop about ASD for Nepalese teachers were asked to the participants. Almost $90 \%$ teachers reported that they agree with this statement $(\mathrm{M}=4.26, \mathrm{SD}=0.98)$. They claimed that Nepalese teacher require more training, seminar and workshop about ASD.

\section{Discussion}

Autism Spectrum Disorders (ASD) is a compound neuro developmental disorder without any exact cause. This implies that ASD bears a brain impairment in a manner that can be seen through the behavior and emotional features of an individual (Blumberg et.al, 2013 as cited in Wheeler et.al, 2015). ASD comprises of a wide assortment of disabilities. Each individual with ASD experiences it in dissimilar ways based on his/her skills, capabilities, and cognition. These distinctions among the children make it hard to effectively train and set up teachers for students 
with ASD. Teachers must be capable to fulfill the needs of all of the children with ASD in their classrooms. The significance of the educators' knowledge and perception concerning ASD turns the attention towards the teacher training programs. Evidence based teacher training programs in relation to ASD ought to be planned more cautiously to offer the essential education for students with ASD (Yasar \& Cronin, 2014; Jung \& Shrestha, 2018).

The rationale of the current study was to assess knowledge, awareness, and attitude of teachers concerning and educating students with ASD in the Nepalese context. Among the available literature, there aren't a lot of studies in Nepal which intended to learn about teachers' knowledge, awareness, attitudes and understanding of ASD. As per my knowledge, there aren't any published studies which have mainly examined Nepali teachers' perspectives regarding ASD in Nepal. As a result, here I wanted to explore the knowledge, awareness and attitude of teachers on the subject of ASD and educating children with ASD in Nepal. I was able to find just one study which explored the understanding of parents and experts' knowledge and awareness of ASD in Nepal.

ASD is a worldwide occurrence. However there is a scarcity of knowledge about how it is perceived and its effect in low-income countries (LICs). On the whole, parents of generally developing kids and experts had only less clarity in awareness about ASD (Heys, Alexander, Medeiros, Tumbahangphe, Gibbons, Shrestha, Manandhar, Wickenden, Shrestha, Costello, Manandhar \& Pellicano, 2016). A study confirmed that the average age of initial symptom of identification in Nepal is approximately 30 months of age. Facilities for children with autism are also very insignificant owing to an intense deficiency of trained experts in this sector. There is a great want for governmental support of better advocacy and further awareness and support programs, in addition to special education and rehabilitation programs (Shrestha \& Santangelo, 2014). The topic of ASD has been not given much attention and the chief cause behind it is the scarcity of nationalized policies and awareness among the Nepalese population. There is a tendency among Nepalese parents to deduce the case of ASD only when their offspring are not able to talk as compared to their general peers (Jung \& Shrestha, 2018). In this state of affairs, teachers' deficiency of knowledge, awareness and attitudes towards ASD is not unexpected. ASD is a reasonably novel health diagnosis in the Nepalese context, with comparatively fewer cases reported before 2004 (Shrestha \& Santengolo, 2014). Without a doubt, Nepali language has not created its own lingo until now to refer to the notion of ASD (Heys et.al., 2016). Consequently, even in my study, I am compelled to use English terminology even in Nepali sentences to refer to ASD and other technical terms. Additionally, Lama (2015) declared that for the effective inclusion of the students with ASD into general schools, teachers' training was mainly vital in conjunction with family and school administration collaboration. Employment of PECS, ABA, Behavioral Therapy, TEACCH were crucial for the educators to manage demanding behaviors displayed by students with ASD. Even the result of this study has uncovered the fact that the knowledge and awareness of teachers concerning ASD and educating children with ASD is inadequate because of lack of teacher training and general methods for treatment of ASD such as applied behavioral analysis (ABA), discrete trial teaching (DTT), developmental individual difference relationship based (DIR), and treatment and education of autistic and communication related handicapped children $(\mathrm{TEACCH})$ etc. 
Students from College of Education in Turkey displayed their understanding about Autism is insufficient but they have the basic comprehension (Yasar \& Cronin, 2014). Pre-service teachers from Turkey, also consisting of special education teachers, did not get adequate training in the area of ASD and they had only some amount of information concerning ASD (Rakap et al., 2016). Nepalese Special education teachers did not possess enough knowledge of ASD because of shortage of training (Jung \& Shrestha, 2018). The result of this study also displayed that special and integrated school teachers of Nepal have same saturation. They possess some degree of knowledge regarding ASD. However the result of this study has been completely different as compared to the results of the students of faculty of education of North Cyprus as they have adequate knowledge regarding ASD (Demirok \& Baglama, 2014). According to the result of this study, Nepalese teachers are aware about ASD in common and majority of teachers know that Autism Spectrum Disorder (ASD) is taken as a neuro developmental disorder which can be improved through education. Similarly, they were not sure about the children with ASD having feeling and emotions. In other words, majority of the teachers stated that children with ASD do not have feeling and emotions. Some teachers (not more than 40\%) were able to provide information about ASD when people asked. However, fifty percent teachers have the knowledge that all children with ASD do not show same behaviors. Vast majority of teachers claimed that they are capable to identify and understand the characteristics of ASD. Results of those statements which were related to knowledge about ASD showed that Nepalese teachers have the general idea of ASD, but they do not have in-depth knowledge of ASD. Knowledge and awareness about ASD is a decisive factor for educators that make them an essential source of social support for the children with ASD. According to the statement of Campbell \& Gillmore (2014), by spreading greater awareness among educators, they would probably be able to assist in the self-reliance of students with ASD and to be supposed as a significant resource of social sustainability. So in Nepal also, teachers should be made aware about ASD through awareness programs and in-depth trainings, so that they can effectively teach students with ASD to make them self-reliant individuals.

The students of faculty of education of North Cyprus stated that they have enough awareness of ASD (Demirok \& Baglama, 2014). On the contrary, this study's result displays that special and integrated teachers of Nepal are not completely aware about ASD. In Nepal, there are no particular teacher training programs on ASD and there are infrequently common teacher training programs for all teachers who have been teaching in the field of special education. The existing situation of ASD is very miserable. There is shortage of training of teachers and know-how regarding IEP in the area of special education. Specially, IEP is very essential for children with ASD than the others disabilities. Due to this fact, children with ASD are compelled to follow the rigid curriculum (Jung \& Shrestha, 2018). Thus, we can infer that there should be more teacher training programs, seminar and workshop about ASD in order to increase the knowledge, understanding and awareness about ASD. According to questionnaire results for second research question, huge numbers of Nepalese teachers lack awareness of educational need of children with ASD. Most of the teachers participated in this study agree to the statement that visual supports don't help much to the students with ASD. As a result, it is true that teachers of Nepal are not aware of ASD. Similarly, Nepalese teachers are able to identify the ASD children or people but most of the teachers do not have experience teaching children with ASD. Due to lack of sufficient knowledge and awareness, most of the teachers claimed that students with ASD 
do not need support to improve their social skill. These result showed that Nepalese teachers are little aware about ASD. Therefore, many awareness programs should be conducted through teacher training, seminar, and workshop.

Educational placement for students with Autism Spectrum Disorder (ASD) is a relevant subject in view of federal legislation sanctioning all children to be educated in the least restrictive environment (LRE). Full inclusion advocates of ASD students consider that the general education location is most suitable to promote complete success, both educationally and socially (Starr, Foy, \& Cramer, 2001). On the contrary, advocates of special schools in more constricted settings like non-public schools (NPS) concentrating in ASD, say that NPS services present more intense educational programming, therefore, giving a better advantage on the whole to the student (Harrower, 1999 as cited in Littin \& Howell, 2013). In view of the argument, it is central to recognize the variables that may distinguish children from being a part of public vs. nonpublic school settings. But, this study showed that students with ASD should be placed in special education classroom rather than general and inclusive classroom or environment settings.

In recent years, placement of students with Autism in educational settings has turned out to be a subject of sharp interest. Within a great educational field, teachers and parents are given the job of deciding the most helpful placement for all students (Tissot, 2011). Lately, inclusion in the common classroom has been considered to accomplish this requirement. Within the inclusive setting in preschool, children with Autism have displayed noteworthy enhancement in intellectual quotient (IQ), social, and communication skills (Stahmer \& Ingersoll, 2004). There is even confirmation of enhancement in adaptive functioning (Fisher \& Meyer, 2002) and span of social interactions with general peers (Whitaker, 2004). Though this conviction is getting much more prevalent, there are still persons who inquire if the inclusion model can accomplish the instructive and social needs of children with ASD (Leyser \& Kirk, 2004). There have even been restricted results in research on including children with ASD to maintain this conviction (Ferraioli $\&$ Harris, 2011). Advocates of a more constricted placement for children with ASD identify the requirement for a more well planned learning environment for many of the students so as to fulfill their educational and social needs (Mesibov \& Shea, 1996 as cited in Littin \& Howell, 2013) and inquire if specialized learning models can be successfully applied in the inclusive setting (Marks, 2007). They also highlight the requirement for specialized instruction to take full advantage of student development and the constructive results that have been acquired from this type of instruction (Reed, Osborne, \& Corness, 2007). On the contrary, this study showed that Nepalese special education teachers hold the view that students with ASD should be placed in special schools rather than general schools. This study also proved that Nepalese teachers are not ready to educate students with ASD in their classes. They are unable to manage the classroom for students with ASD, to plan lesson and to conduct appropriate learning activities, and to integrate new teaching strategies in classrooms. So we can see that Nepalese teachers are not prepared to effectively teach children with ASD. Finally, this study clarified that Nepalese teachers should have more training, seminar and workshop about ASD. Moreover, Nepalese teachers themselves agreed in this study, that they require more training, workshops and seminars in the field of educating children with ASD. 
Perspectives of Teachers on Autism Spectrum Disorders (ASD) in Nepal/ 203

\section{Conclusion}

In sum, special and integrated teachers in Nepal showed their knowledge, awareness, understanding, attitudes, placement services, teaching readiness, and educational need of children with ASD is limited. However, they have the basic knowledge of ASD and they are providing services as per their knowledge and skills. They require better education and training to utilize evidence-based practices while they are teaching students with ASD. They have a little amount of theoretical knowledge and skill but they require practical approaches and assistive technology (AT). This research suggests that separate ASD teacher training program be established and conducted. Apart from this, special education discipline should also be included while conducting the general teacher training programs.

Literature supports the view that general settings are the least restrictive environment (LRE) for students with ASD but teachers in Nepal still hold the view that separate settings are suitable for such children. As we can see, Nepalese teachers are not prepared to teach children with ASD and they don't have adequate knowledge and professional skills to deal with them. They also agreed that they need more trainings, workshops and seminars to enhance their skills and knowledge in this field. If educators lack skills, awareness and knowledge concerning ASD, it won't be possible to care for the children through education, to bring progress in their problem behaviors, to develop their daily life skills and enhance their family life. Consequently, only the educators who possess sufficient knowledge, skills, training concerning ASD will be able to create a constructive change and encourage independence in students with ASD.

A handful of attempts have been made by some NGOs to create awareness, educate students, train parents, advocate for individuals with ASD and provide training to the educators for teaching children with ASD but it is not sufficient. Now, both governmental agencies and nongovernmental organizations of Nepal should be active for the increases of not only teachers' knowledge, awareness and attitudes but also other related clients like parents, professionals, society and community.

\section{Limitations of the study}

There are some limitations of this study. Primarily, this study was carried out during the training time called "Best Practices in Special Needs Education" and there were teachers only from Kathmandu valley not other parts of Nepal. Subsequently, the result of this study might not be generalized among the entire special and integrated teacher population of Nepal. Owing to different reasons, teachers who have been particularly employed in ASD schools were not included during this training period. Furthermore, this study reflects gender during the training because there was extra participation of female teachers in this study $(65 \%)$. Thus, the result of the study might be different based on the participants' gender. As per this sample, sample of male/female attitudes and knowledge could not be established.

An added limitation of this study was that data was gathered in a limited duration of 30 minutes in the midst of the training hours. If participants had been given sufficient time to reflect on these questions/statements, they possibly would have provided more detailed responses. 


\section{Implications of the study}

This study is a novel subject in the sector of special needs education (chiefly in the field of ASD) in the Nepalese context. This study is quantitative and it generates several opportunities for additional research, regarding knowledge/ awareness of ASD and teaching students with ASD. This study's result will be useful to the Nepalese government and other NGOs for teaching students with ASD, organizing training programs for teachers and to create plan, policies, and strategies associated with the ASD field. Similarly, this study will uncover the actuality of teachers' knowledge awareness and attitudes towards ASD which will assist in realizing how to advance ahead in Nepal.

This study also adds in raising the skill level, imparting ample knowledge and shifting the perspectives of the educators towards disability, particularly in the area of ASD in the Nepalese context. This study will play a key role in giving Nepalese special and integrated teachers with expertise and suitable information to extend associated polices, programs, and teacher training programs mainly in the initial phase, in the near future.

\section{References}

American Psychiatric Association. (2013). Diagnostic and Statistical Manual of Mental Disorders (5th ed.). Arlington, VA: Author.

Bogdan, R. C., \& Biklen, S. (2007). Qualitative research for education: An introduction to theories and methods (5th ed.). USA: Pearson Education Inc.

Campbell, M. \& Gilmore, L. (2014). The importance of social support for students with intellectual disability: An intervention to promote mental health and well-being. Cypriot Journal of Educational Sciences, 9 (1), 21-28.

Central Bureau of Statistics. (2012). National population and housing census 2011. Kathmandu: National Planning Commission Secretariat. Retrieved December 13, 2018, from http:// unstats.un.org/unsd/demographic/sources/census/wphc/Nepal/Nepal-Census-2011-Voll.pdf

Creswell, J. W. (2012). Educational research (4th ed.). New Delhi: PHI Learning Private Limited.

Curriculum Developmental Centre. (2016). Curriculum for mentally disabled children. Nepal, Sanothimi: Author.

Demirok, M. S. \& Baglama, B. (2014). Perspectives of faculty of education students on autism spectrum disorders in North Cyprus. Elsevier, 190, 399-408.

Ferraioli, S. J., \& Harris, S. L. (2011). Effective educational inclusion of students on the autism spectrum. Journal of Contemporary Psychotherapy, 41, 19 -28.

Gargiulo, R. M. (2003). Special education in contemporary society: An introduction to exceptionality. Belmont CA: WADSWORTH, Thomson Learning, Inc.

Harris, S. L. \& Handleman, J. S. (2000). Age and IQ at intake as predictors of placement for young children with autism: A foru-to six year follow-up. Journal of Autism and Developmental Disorders, 30 (2), 137-142. 
Perspectives of Teachers on Autism Spectrum Disorders (ASD) in Nepal/ 205

Helfin, L. J., \& Alaimo, D. F. (2014). Students with autism spectrum disorders: effective instruction practices. USA: Prentice Hall.

Heys, M., Alexander, A., Medeiros, E., Tumbahangphe, K. M., Gibbons, F., Shrestha, R., Manandhar, M., Wickenden, M., Shrestha, M., Costello, A., Manandhar, D., \& Pellicano, E. (2016). Understanding parents' and professionals'knowledge and awareness of autism in Nepal. Sage journal, Retrieved June 5, 2018 from (https://pdfs.semanticscholar.org/cb b5/00811152bec158c542597b8801beb59960c3.pdf).

Jung, D. Y. \& Shrestha, S. H. (2018). A Comparative Study between Special and Ingegrated School Teachers' Perspectives on Autism Spectrum Disorders (ASD) in Nepal. Journal of emotional \& behavioral disorders, 34 (4), 403-421.

Jung, D. Y. \& Shrestha, S. H. (2018). Issues and barriers to educating children with autism spectrum disorders in Nepal. Journal of emotional \& behavioral disorders, 34 (2), 31-49.

Kaul, L. (2009). Methodology of educational research (4th ed.). New Delhi: Vikas Publishing House Pvt. Ltd.

Kirk, S., Gallagher, J., \& Coleman, M. R. (2015). Educating exceptional children (14th ed.). United State of America: CENGAGE Learning.

Labarbera, R. (2019). Educating Students with Autism Spectrum Disorders: Partnering with Families for Positive Outcomes (4th ed.). New Delhi: SAGE Publication Pvt. Ltd.

Lama, M. (2015). Teacher's perspectives on the inclusion of children with Autism in Mainstream schools. (Unpublished Master Thesis). Padmakanya Multiple Campus, Tribhuvan University, Kathmandu, Nepal.

Lane, K. L., Carter, E. W., Common, E., \& Jordan, A. (2012). Teacher expectations for students performance: Lesson learned and implications for research and practice. IN B. G. Cook, M. Tankersley, \& T. J. Landrum (Eds.), Classroom behavior, context, and interventions, 95-129. Bingley, UK: Emerland Publishing Group.

Leyser, Y., \& Kirk, R. (2004). Evaluating inclusion: An examination of parent views and factors influencing their perspectives. International Journal of Disability, Development, and Education, 51, 271-285.

Littin, L. L. S. \& Howell, E. (2013). Educational placement for children with autism spectrum disorders in public and non-public school settings: The impact of social skills and behavior problems. Education and Training in Autism Developmental Disabilities, 2013, 48 (4) 469-478.

Marks, S. U. (2007). Can "special" programs for children with autism spectrum disorders be inclusive? Research \& Practice for Persons with Severe Disabilities, 32, 265-268.

Matson, J. L., \& Kozlowski, A. M. (2011). The increasing prevalence of autism spectrum disorders. Research in Autism Spectrum Disorders, 5, 418-425.

Mehring, T.A. \& Dow, M.J. (2001). Preparing future teachers for students with autistic spectrum disorders. In T. Wahlberg, F. Obiakor, S. Burkardt, \& A.F. Rotarori (Eds.), Autistic 
Spectrum Disorders: Educational and Clinical Interventions (pp. 69-88). Oxford: Elsevier Science.

National Center for Educational Development. (2016). Disability and education for disable children: Disable basic training self materials. Sanothimi, Bhaktapur: Author.

National Institute of Health (NIH), U.S. Department of Health and Human Services, \& National Institute on Deafness and Other Communication Disorders. (2012). Communication problem in children with autism spectrum disorders. Retrieved February 3, 2019, from https://www.nided.nih.gov/health/autism-spectrum-disorder-communicationproblems-children

Rakap, S., Balikci, S., \& Parlak-Rakap, A. (2016). An analysis of Turkish pre-service teachers' knowledge of autism spectrum disorder: Implications for teacher's preparation programs. Sage Open, July-september 2016: 1-11.

Reed, P., Osborne, L., \& Corness, M. (2007). Brief report: Relative effectiveness of different homebased behavioral approaches to early teaching intervention. Journal of Autism and Developmental Disorders, 37, 1815-1821.

Robertson, K., Chamberlain, B. \& Kaasari, C. (2003). General education teachers' relationships with included students with autism. Journal of Autism and Developmental Disorders, 33 (2), 123-130.

Rodriguez, I. R., Saldana, D. \& Moreno, F. J. (2011). Support, inclusion, and special education teachers' attitudes towards the education of students with autism spectrum disorders. Autism Research and Treatmnet, 2012, 1-8.

Shrestha, M., \& Santangelo, S. L. (2014). Autism: Challenge in Nepal. In V. B. Patel, V. R. Preedy, \& C. R. Martin, (Eds.), Comprehensive guide to autism. Section, (pp. 24972507). Retrieved April 4, 2018 from https://link.spring.com/referenceworkentry/ 10.1007\%2f978-1-4614-4788-7_179\#page-1

Singh, A. K. (2006). Test, measurement and research methods in behavioral science. Patna: Bharati Bhawan.

Siu, A. F. Y. \& Ho, E. L. S. (2010). Relations between commitment to a treatment orientation and selfefficacy among teachers working with children with autism. International Journal of Early Childhood Special Eduction, 2 (3), 180-192.

Stahmer, A. C., \& Ingersoll, B. (2004). Inclusive programming for toddlers with autism spectrum disorders: Outcomes from the Children's Toddler School. Journal of Positive Behavior Interventions, 6, 67-82.

Starr, E. M., Foy, J. B., \& Cramer, K. M. (2001). Parental perceptions of the education of children with pervasive developmental disorders. Education and Training in Mental Retardation and Developmental Disabilities, 36, 55- 68.

Tissot, C. (2011). Working together? Parent and local authority views on the process of obtaining appropriate educational provision for children with autism spectrum disorders. Educational Research, 53, 1-15. 
Urea, I. R. (2013). The role of the teacher's communication style on the pupil's attitude towards the learning process. Cypriot Journal of Educational Sciences. 8 (4), 447-456.

Weintraub, K. (2011). Autism counts. Nature, 479, 22-24.

Wheeler, J. J., Mayton, M. R., \& Carter, S. L. (2015). Methods for teaching students with autism spectrum disorders: Evidence-based practices. Boston, MA: Pearson Education.

Whitaker, P. (2004). Fostering communication and shared play between mainstream peers and children with autism: Approaches, outcomes, and experiences. British Journal of Special Education, 31, 215-222.

Yasar, P. \& Cronin, K. A. (2014). Perspectives of College of Education Students in Turkey on Autism Spectrum Disorders. International Journal of Special Education, 29 (1), 1-15. 